\title{
Beneficial effect of nasal saline irrigation in children with allergic rhinitis and asthma: A randomized clinical trial
}

\author{
Minyoung Jung, ${ }^{1,2}$ Ji Young Lee, ${ }^{3}$ Gwanghui Ryu,${ }^{4}$ Kyung Eun Lee, ${ }^{4}$ Sang Duk Hong, ${ }^{4}$ Jaehee Choi, ${ }^{5}$ Soyoung Kim, ${ }^{2}$ Kangmo Ahn, ${ }^{2,6}$ \\ Hun-Jong Dhong, ${ }^{4}$ Seung-Kyu Chung, ${ }^{4}$ Jihyun Kim, ${ }^{2,6}$ Hyo Yeol Kim ${ }^{4}$
}

\begin{abstract}
Background: Asthma and allergic rhinitis (AR) are chronic inflammatory diseases of airway and affect the disease severity each other.

Objective: We performed this study to examine whether nasal saline irrigation (NSI) improves bronchial hyperresponsiveness and clinical parameters in children with asthma and allergic rhinitis (AR).

Methods: We enrolled 20 children with AR and asthma aged between 6-18 years. Patients were randomized into two groups: irrigation group ( 8 boys and 2 girls) and control group ( 8 boys and 2 girls). The irrigation group performed daily NSI. All patients received 12 -week treatment with montelukast, levocetirizine, and inhaled glucocorticoids. Provocative concentrations of methacholine causing a $20 \%$ decrease in $\mathrm{FEV}_{1}\left(\mathrm{PC}_{20}\right)$, Asthma Control Test (ACT), the Questionnaire for Quality-of-Life Specific to Allergic Rhinitis in Korean Children (QQOL-ARK) and exhaled nitric oxide $\left(\mathrm{FE}_{\mathrm{NO}}\right)$ were compared before and after the study.
\end{abstract}

Results: The $\mathrm{PC}_{20}$ at week 12 was higher than baseline measurements in the irrigation group $(P=0.017)$, while there was no difference in $\mathrm{PC}_{20}$ before and after treatment in the control group $(P=0.333)$. ACT score increased after 12 weeks of NSI $(P=0.007)$, while QQOL-ARK score decreased compared to baseline scores $(P=0.028)$ in the irrigation group. No differences in ACT and QQOL-ARK were found between weeks 0 and 12 in the control group. No differences were found in the median value of changes in $\mathrm{PC}_{20}, \mathrm{ACT}$, QQOL-ARK and $\mathrm{FE}_{\mathrm{NO}}$ between the irrigation and control groups.

Conclusions: Our results suggest that NSI is beneficial for treatment of asthma and AR in children.

Key words: hypersensitivity, obstructive lung disease, asthma, allergic rhinitis, allergic disease, symptom score

\section{From:}

Department of Pediatrics, Kosin University Gospel Hospital, Kosin University College of Medicine, Busan, Korea

${ }^{2}$ Environmental Health Center for Atopic Diseases, Samsung Medical Center, Seoul, Korea

Department of Pediatrics, Hallym University Hangang Sacred Heart Hospital

${ }^{4}$ Department of Otorhinolaryngology-Head and Neck Surgery, Samsung Medical Center, Sungkyunkwan University School of Medicine, Seoul, Korea

${ }^{5}$ Department of Pediatrics, Sahmyook Medical Center, Seoul, Korea

${ }^{6}$ Department of Pediatrics, Samsung Medical Center, Sungkyunkwan University School of Medicine, Seoul, Korea

\section{Introduction}

Asthma and allergic rhinitis (AR) are chronic inflammatory diseases of the airway that are major global health problems in the pediatric population. ${ }^{1}$ Both asthma and AR negatively affect quality of life and school performance, and result

\author{
Corresponding author: \\ 1. Jihyun Kim \\ Department of Pediatrics, Samsung Medical Center, Sungkyunkwan \\ University School of Medicine \\ 81 Irwon-ro, Gangnam-gu, Seoul, 06351, Korea \\ E-mail: jhlovechild@gmail.com \\ 2. Hyo Yeol Kim \\ Department of Otorhinolaryngology-Head and Neck Surgery, \\ Samsung Medical Center, Sungkyunkwan University School of \\ Medicine \\ 81 Irwon-ro, Gangnam-gu, Seoul, 06351, Korea \\ E-mail: siamkhy@gmail.com
}

in substantial economic burdens. ${ }^{2}$ More than two-thirds of patients with asthma concurrently have rhinitis, and $20-50 \%$ of patients with AR also have respiratory symptoms and clinical features of asthma. ${ }^{3}$ Bronchial hyperresponsiveness (BHR) 
to direct or indirect stimuli is frequently observed in patients with $\mathrm{AR}$ and often improves after AR treatment. ${ }^{4-6}$ When patients with AR are directly exposed to an allergen, inflammatory mediators may propagate to the lower airways through postnasal drip and the systemic circulation, leading to disrupted bronchial epithelium. ${ }^{7}$ These findings indicate that a combined strategy to treat the upper and lower airways could lead to better outcomes in pediatric patients with asthma and $\mathrm{AR}$, supporting the 'united airway disease' concept.

Nasal saline irrigation (NSI) has been studied as an adjunctive non-pharmacologic treatment in sinonasal diseases including $\mathrm{AR}$, chronic rhinosinusitis (CRS), and acute upper respiratory tract infection. ${ }^{8-10}$ Mechanical cleansing with solution could remove thick mucus, debris, allergens, and inflammatory secretions from the nasal cavity and paranasal sinuses. ${ }^{11,12}$ A recent systematic review showed that daily NSI had some benefit on CRS treatment in adults compared with placebo. ${ }^{10}$ In addition, NSI significantly improved rhinitis scores and decreased the use of oral antihistamines in children with AR. ${ }^{13}$ However, there are few studies regarding the therapeutic effects of NSI on asthma in children as well as adults.

In this randomized, controlled, prospective trial, we examined whether NSI improves BHR and clinical parameters in children with asthma and AR.

\section{Methods}

\section{Study design and populations}

We enrolled 20 patients with asthma and AR between 6 and 18 years of age from May 2015 to June 2016 and complete the study at September 2016. Asthma was diagnosed by a physician based on clinical symptoms and positive BHR, which was defined as either bronchodilator reversibility of at least $12 \%$ in forced expiratory volume in 1 second $\left(\mathrm{FEV}_{1}\right)$ or provocation concentration of methacholine causing a $20 \%$ fall in $\mathrm{FEV}_{1}\left(\mathrm{PC}_{20}\right)$ less than $8 \mathrm{mg} / \mathrm{mL}$ at the screening visit. $\mathrm{AR}$ was defined as clinical symptoms including rhinorrhea, nasal obstruction, nasal itching, and sneezing and the presence of any specific IgE on skin prick test. Exclusion criteria were (1) history of recent purulent rhinosinusitis, otitis media, or paranasal sinus defects, (2) abnormal nasal ciliary function or immunodeficiency, (3) cognitive impairment, and (4) FEV less than $60 \%$ of the predicted value.

The institutional review board of Samsung Medical Center approved this study protocol (SMC IRB file No. 2014-07-162), and written informed consent was obtained from patients and their parents before beginning the study. The study protocol was registered in the WHO International Clinical Trials Registry Platform (ICTRP) with the registration number KCT0001860.

\section{Randomization and intervention}

Block randomization was performed with a block size of 2 . The subjects were randomly assigned to the irrigation group or the control group within a block. The irrigation group was instructed to rinse their nasal cavities using a disposable syringe with $60-150 \mathrm{~mL}$ of isotonic saline twice per day on a daily basis during 12 weeks. ${ }^{14}$ We instructed the study participants to use commercial sterile isotonic saline and disposable syringe to keep a good hygiene. All patients and their caretakers were educated by an experienced nurse using a video clip. ${ }^{15}$ All patients continued step 2 treatment according to the Global Initiative for Asthma guidelines ${ }^{1}$ and levocetirizine $5 \mathrm{mg}$ for AR throughout the study period. Asthma controllers included ciclesonide $80 \mu \mathrm{g} /$ day or montelukast (5 mg for 6-14 years olds, or $10 \mathrm{mg}$ for those older than 14 years). An open-label inhaler of salbutamol (100 $\mu \mathrm{g}$ per puff) was provided as a rescue medication. Intranasal corticosteroids were not allowed during the trial.

\section{Clinical evaluation and laboratory tests}

To ensure participant compliance, patients were followed by the same pediatric allergist (JK) every 4 weeks. A skin prick test (SPT) was performed at enrollment and included common allergens such as house dust mite (Dermatophagoides pteronyssinus, D. farinae), grass pollen (timothy, bermuda, meadow grass), tree pollen (alder, birch, elder, oak, japanese cedar), weed pollen (mugwort, ragweed, short ragweed, hops Japaneses, fat hen), animal (cat, dog), mold (Alternaria alternata, Aspergillus fumigatus, Cladosporium, Penicillium), and food (wheat, cow's milk, whole egg, soybean, peanut). Histamine was used as a positive control and normal saline was used as a negative control. All extracts were manufactured by Allergopharma (Merck KGaA, Darmstadt, Germany). A positive SPT response was considered when the mean wheal diameter was $\geq 3 \mathrm{~mm}$ larger than the negative control. In addition, otorhinolaryngologists performed sinonasal endoscopic examination, and sinonasal plain X-rays were obtained to exclude rhinosinusitis, nasal anatomical defects, or paranasal sinus defects.

At weeks 0 and 12, measurements were performed for $\mathrm{FEV}_{1}, \mathrm{PC}_{20}$, fractional exhaled nitric oxide $\left(\mathrm{FE}_{\mathrm{NO}}\right)$, AR severity, asthma control test (ACT), questionnaire for quality-of-life specific to $\mathrm{AR}$ in Korean children (QQOL-ARK), and eosinophils (\%) in nasal secretions. We presented BHR as the values of $\mathrm{PC}_{20}$ which determined by methacholine challenge test using a method described by Chai et al. ${ }^{16}$ The pulmonary technician was blinded to the group to which the subject belonged. Concentration of $0.075,0.15,0.31,0.62,1.25,2.5,5$, 10 and $25 \mathrm{mg} / \mathrm{mL}$ methacholine were diluted with buffered saline. After baseline pulmonary function measured, aerosol was generated using the Pulmo Aide nebulizer (Devilbiss Healthcare, Somerset, PA, USA) with a KoKo-MSM analog micro-dosimeter (nSpire Health Inc., Louisville, CO, USA). We measured $\mathrm{FEV}_{1}$ at 90 seconds after five breath of each diluted methacholine aerosol increasing concentrations of methacholine until a $20 \%$ decrease in $\mathrm{FEV}_{1}$ was detected. We calculated the $\mathrm{PC}_{20}$ using the guideline formula. ${ }^{17}$ The $\mathrm{FE}_{\mathrm{NO}}$ level was measured with an electrochemical analyzer (NIOX MINO, Aerocrine, Solna, Sweden) according to the American Thoracic Society guidelines. ${ }^{18}$ The severity of AR was classified as mild intermittent, mild persistent, moderate/severe intermittent, and moderate/severe persistent according to the $\mathrm{Al}$ lergic Rhinitis and its Impact on Asthma guideline. ${ }^{19}$ The ACT scores assessed daytime and nighttime symptoms and rescue bronchodilator use on a $0-6$ scale, and higher scores represent better control. The QQOL-ARK consists of 18 items rated on a 5-point scale, and a high score indicates low quality of life..$^{20}$ 
The frequency of NSI, adverse events, and presence of asthma exacerbations were also monitored at every visit. Asthma exacerbations were defined as worsening of respiratory symptoms requiring systemic corticosteroids, emergency department (ED) visits, or hospitalization. ${ }^{21}$

In the irrigation group, patients who did not adhere adequately to the assigned regimen dropped out as follows: NSI used less than four days per week or the use of another fluid instead of normal saline. Any patient diagnosed with acute otitis media or acute rhinosinusitis or showing poor compliance to usual treatment during follow up visits was excluded.

\section{Statistical analysis}

Sample size was determined on the estimate of a $4 \mathrm{mg} / \mathrm{ml}$ difference in $\mathrm{PC}_{20}$ between the irrigation and control groups based on a pilot showing that 8 patients would be needed in each group (90\% power and 5\% significance). To allow for a $20 \%$ dropout rate, we aimed to enroll 10 patients per group. The primary outcome was changes in BHR presented as differences in $\mathrm{PC}_{20}$ between weeks 0 and 12. The secondary endpoints were changes in ACT and QQOL-ARK scores, eosinophils (\%) in nasal secretions, $\mathrm{FE}_{\mathrm{NO}}$ between weeks 0 and 12 , and rate of asthma exacerbation events.

Statistical analysis was performed using SPSS 23.0 software (SPSS Inc., Chicago, IL, USA). Differences in gender, allergic sensitization, medication usage, and exacerbation rates between the two groups were analyzed using Fisher's exact test. Age, proportion of eosinophils in nasal secretions, $\mathrm{FEV}_{1}$, $\mathrm{PC}_{20}, \mathrm{FE}_{\mathrm{NO}}, \mathrm{ACT}$, and QQOL-ARK at baseline were compared between the two groups using the Mann-Whitney $U$ test.
The analysis of changes in $\mathrm{PC}_{20}, \mathrm{FEV}_{1}, \mathrm{AR}$ severity, $\mathrm{FE}_{\mathrm{NO}}$, ACT, QQOL-ARK, and the proportion of eosinophils in nasal secretions from baseline to week 12 was performed with the Wilcoxon singed rank test and Fisher's exact test. The changes in $\mathrm{PC}_{20}$, ACT, and QQOL-ARK and the percentage change of $\mathrm{FEV}_{1}$ and $\mathrm{FE}_{\mathrm{NO}}$ were compared between the two groups using the Mann-Whitney $U$ test. $P$ value $<0.05$ was considered significant.

\section{Results}

Of the 20 patients who met the eligibility criteria, 10 each ( 8 boys and 2 girls per group) were randomly assigned to the irrigation and control groups (Figure 1). All subjects completed this study without withdrawal due to poor compliance or serious adverse events. Clinically, 4 (40.0\%) and $6(60.0 \%)$ patients in the irrigation group had mild persistent and moderate-to-severe persistent AR, while 3 (30.0\%), 1 (10.0\%), and $6(60.0 \%)$ patients in the control group had mild persistent, moderate-to-severe intermittent, and moderate-to-severe persistent AR. There were no differences in baseline characteristics such as age, total IgE, proportion of eosinophils, sensitization rates, pulmonary function tests, $\mathrm{PC}_{20}, \mathrm{FE}_{\mathrm{NO}}, \mathrm{AR}$ severity, ACT, and QQOL-ARK between the intervention group and control group (Table 1). In addition, no differences were found in the use of asthma controllers between the two groups during the study period. In the intervention group, median (interquartile range, IQR) irrigation frequency per week was 7 (5-7) days.
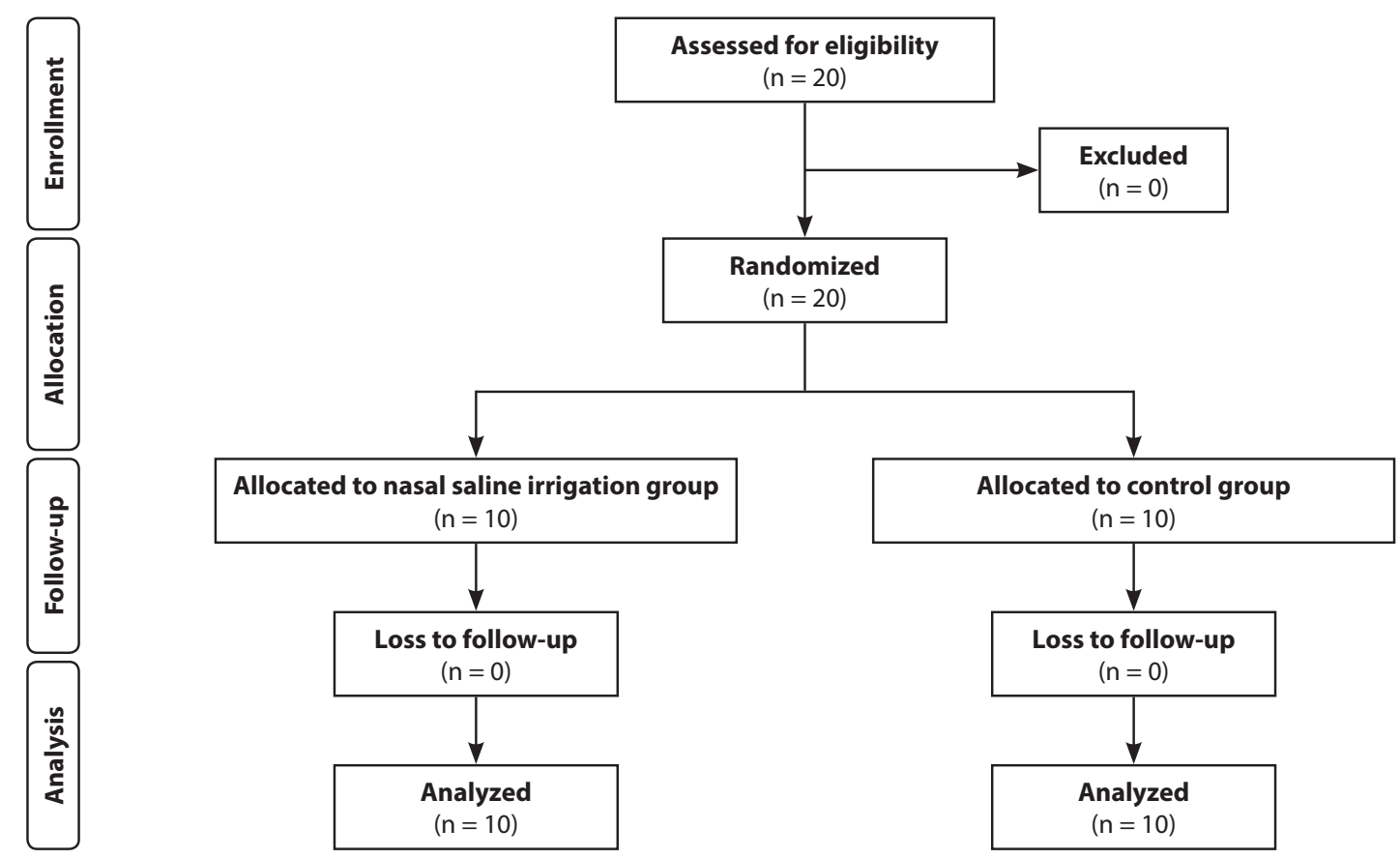

Figure 1. Flowchart of the study population. 
Table 1. Baseline characteristics of the participants

\begin{tabular}{|c|c|c|c|}
\hline & Irrigation group $(n=10)$ & Control group $(n=10)$ & $P$ value \\
\hline Age $(\mathrm{yr})^{*}$ & $8.7(7.9-10.7)$ & $9.7(7.3-11.5)$ & 0.739 \\
\hline Male (no, \%) & $8(80)$ & $8(80)$ & 1.000 \\
\hline Total IgE $(\mathrm{kU} / \mathrm{L})^{*}$ & $293.0(130.8-605.0)$ & $632.0(171.0-1165.0)$ & 0.356 \\
\hline Nasal eosinophils (\%)* & $3.5(0.5-11)$ & $1.0(0-2.0)$ & 0.222 \\
\hline Sensitization rate (no, \%) & $10(100)$ & $10(100)$ & 1.000 \\
\hline House dust mites & $7(70.0)$ & $7(70.0)$ & 1.000 \\
\hline Tree pollen & $4(40.0)$ & $8(80.0)$ & 0.170 \\
\hline Grass pollen & $4(40.0)$ & $3(30.0)$ & 1.000 \\
\hline Weed pollen & $3(30.0)$ & $5(50.0)$ & 0.650 \\
\hline Animals & $4(40.0)$ & $8(80.0)$ & 0.170 \\
\hline Molds & $3(30.0)$ & $3(30.0)$ & 1.000 \\
\hline \multicolumn{4}{|l|}{ Spirometry ${ }^{*}$} \\
\hline FVC (\% predicted value) & $98.0(90.0-103.0)$ & $93.5(85.0-103.0)$ & 0.436 \\
\hline $\mathrm{FEV}_{1}(\%$ predicted value $)$ & $85.0(79.0-90.0)$ & $84.5(80.0-91.0)$ & 0.853 \\
\hline $\mathrm{FEV}_{1} / \mathrm{FVC}$ & $81.0(77.0-86.0)$ & $80.5(78.0-86.0)$ & 0.739 \\
\hline $\mathrm{PC}_{20}(\mathrm{mg} / \mathrm{mL})^{*}$ & $0.68(0.41-2.72)$ & $1.14(0.77-2.22)$ & 0.436 \\
\hline $\mathrm{FE}_{\mathrm{NO}}(\mathrm{ppb})^{*}$ & $39.0(32.0-52.0)$ & $49.5(32.0-72.0)$ & 0.436 \\
\hline AR severity (no, \%) & & & 1.000 \\
\hline Mild persistent & $4(40)$ & $3(30)$ & \\
\hline Moderate-to-severe intermittent & 0 & $1(10)$ & \\
\hline Moderate-to-severe persistent & $6(60)$ & $6(60)$ & \\
\hline ACT score ${ }^{*}$ & $18(17.3-21.0)$ & $18(17.0-22.8)$ & 0.604 \\
\hline QQOL-ARK score* & $15(10.0-25.8)$ & $16(10.0-18.3)$ & 0.971 \\
\hline Asthma controller (no, \%) & $8(80.0)$ & $8(80.0)$ & 1.000 \\
\hline LTRA & $7(70.0)$ & $7(70.0)$ & 1.000 \\
\hline Inhaled corticosteroids & $3(30.0)$ & $3(30.0)$ & 1.000 \\
\hline
\end{tabular}

$\mathrm{FVC}$, forced vital capacity; $\mathrm{FEV}_{1}$, forced expiratory volume in 1 second; $\mathrm{PC}_{20}$, provocative concentration of methacholine causing a $20 \%$ decrease in $\mathrm{FEV}_{1}$; $\mathrm{FE}_{\mathrm{NO}}$, fractional exhaled nitric oxide; ACT, Asthma Control Test; QQOL-ARK, Questionnaire for Quality-of-Life Specific to Allergic Rhinitis in Korean Children; LTRA, leukotriene receptor antagonist

*Values are presented as median and interquartile range.

For the primary endpoint, 12 weeks of treatment with NSI resulted in significant improvement in BHR compared with the control group (Figure 2). The $\mathrm{PC}_{20}$ at week 12 was higher than baseline measurements in the irrigation group $(P$ $=0.017$ ), while no difference was observed in $\mathrm{PC}_{20}$ between week 0 and week 12 in the control group $(P=0.333)$. However, no difference was found in the median value of changes in $\mathrm{PC}_{20}$ between the irrigation and the control groups $(2.91 \mathrm{mg} /$ $\mathrm{mL}$ [IQR, 0.26 to 11.07$]$ vs. $0.61 \mathrm{mg} / \mathrm{mL}$ [IQR, -0.59 to 3.13$]$ ) $(P=0.186)$.
For the key secondary endpoints, ACT score increased after 12 weeks of NSI $(P=0.007)$, while QQOL-ARK score was reduced compared to baseline scores $(P=0.028)$ in the irrigation group (Figures 3 and 4). The proportion of patients with moderate-to-severe persistent AR decreased from $60 \%$ to $30 \%$ in the irrigation group $(P=0.003)$, while no difference in the distribution of AR severity was found in the control group $(P=0.094)$ (Figure 5). There were no differences in ACT and QQOL-ARK scores between week 0 and week 12 in the control group ( $P=0.074$ and 0.112 , respectively). In addition, no differences were observed in the median value of change in ACT and QQOL-ARK scores between the irrigation and control groups $(P=0.123$ and 0.315 , respectively). 


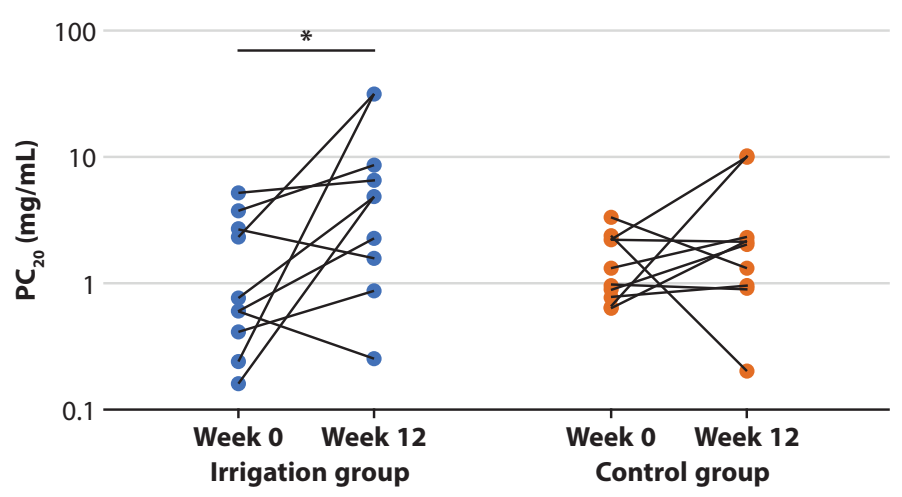

Figure 2. Change in provocative concentration of methacholine causing a $20 \%$ decrease in forced expiratory volume in 1 second $\left(\mathrm{PC}_{20}\right)$ between week 0 and week 12. The $\mathrm{PC}_{20}$ at week 12 was higher than baseline measurements in the irrigation group $(P=0.017)$, while no difference was observed in $\mathrm{PC}_{20}$ in the control group $(P=0.333) .{ }^{\star} P<0.05$

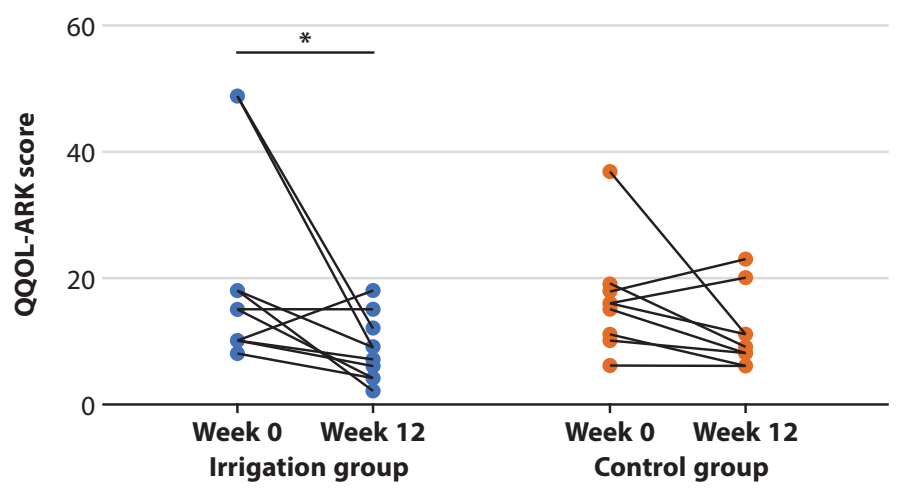

Figure 4. Change in Questionnaire for Quality-of-Life Specific to Allergic Rhinitis in Korean Children (QQOL-ARK) score between week 0 and week 12. The QQOL-ARK score at week 12 was higher than baseline measurements in the irrigation group $(P=\mathbf{0 . 0 2 8})$, while no difference was observed in the control group $(P=0.112) .{ }^{\star} P<0.05$

There were no differences in $\mathrm{FEV}_{1}, \mathrm{FE}_{\mathrm{NO}}$, or proportion of eosinophils in nasal secretions between pre- and post-treatment in either group (all $P>0.05$ ). No differences were observed in the percentage change of $\mathrm{FEV}_{1}, \mathrm{FE}_{\mathrm{NO}}$ and nasal eosinophils between the two groups at the end of the study.

During the study period, 1 of 10 patients $(10 \%)$ in the irrigation group and 3 of 10 patients (30\%) in the control group had a history of asthma exacerbation requiring oral corticosteroids or ED visits $(P=0.582)$. No patient in either group was admitted to the hospital due to asthma exacerbation. Three patients in the irrigation group complained of otalgia, ear fullness, and/or epistaxis, but they all recovered within 3 days without additional medication. In addition, no severe adverse events causing cessation of NSI were noted during the study period.

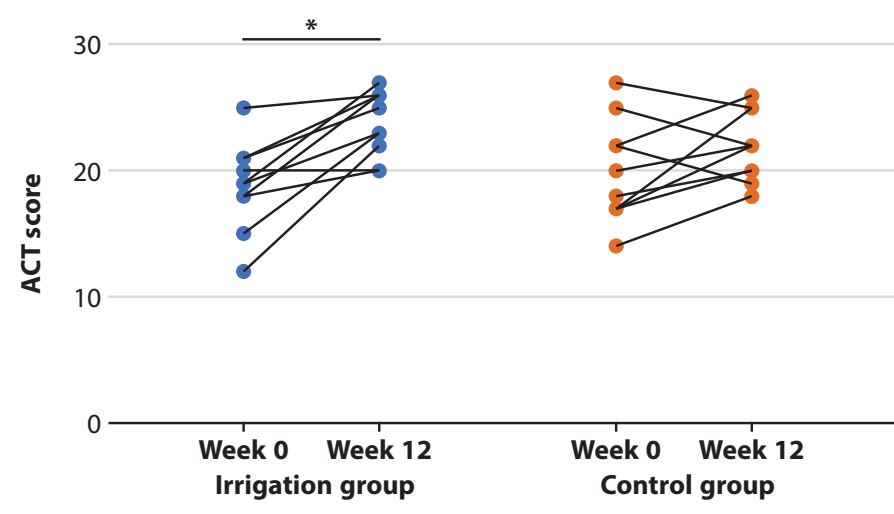

Figure 3. Change in Asthma Control Test (ACT) score between week 0 and week 12. ACT score at week 12 was higher than baseline measurements in the irrigation group ( $P$ $=0.007)$, while no difference was observed in the control group $(P=0.074) .{ }^{\star} P<0.05$

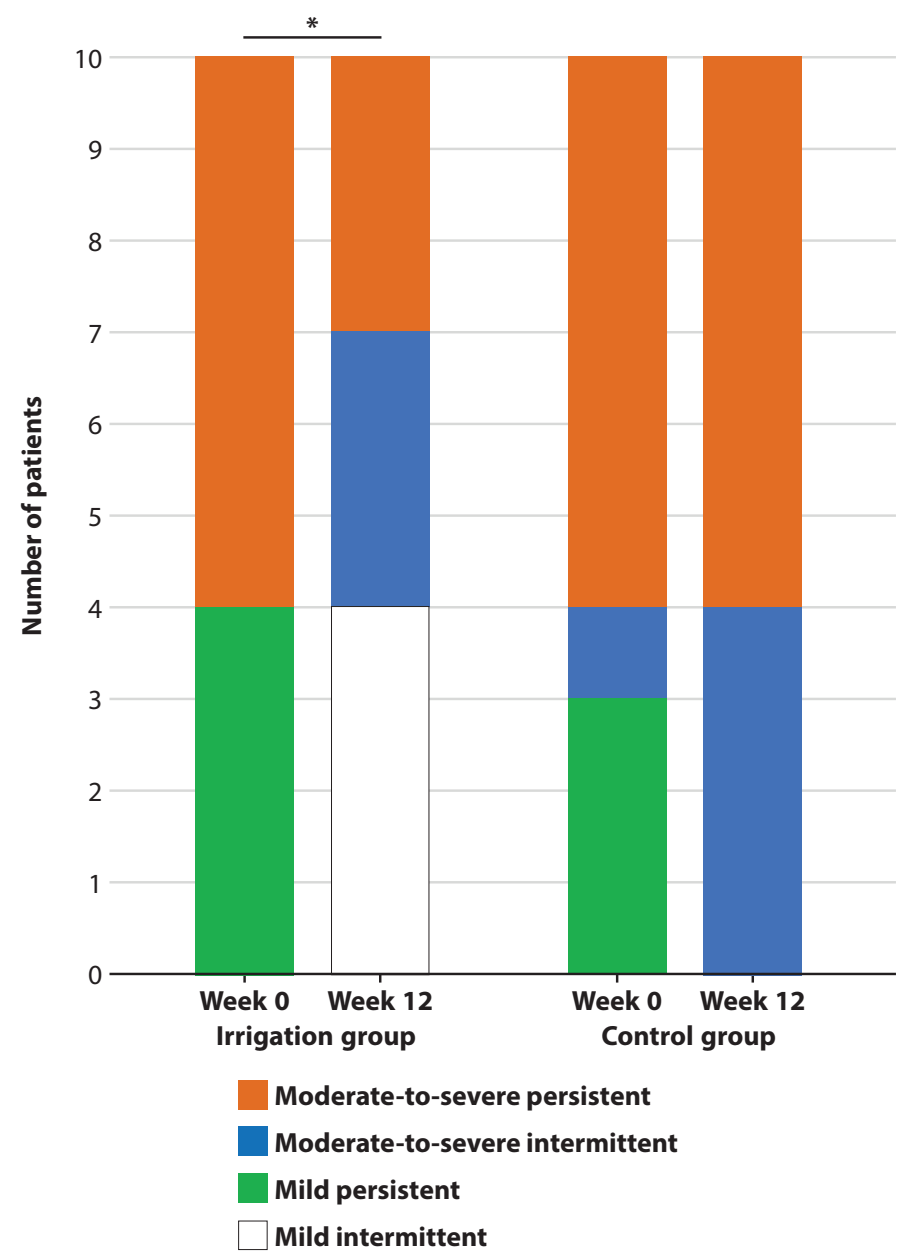

Figure 5. Change in distribution of AR severity between week 0 and week 12. The proportion of patients with moderate-to-severe persistent AR decreased from $60 \%$ to $30 \%$ in the irrigation group $(P=\mathbf{0 . 0 0 3})$, while no difference in distribution of AR severity was found in the control group ( $P$ $=0.094) .{ }^{\star} P<0.05$ 


\section{Discussion}

To the best of our knowledge, this is the first randomized controlled trial demonstrating that NSI was effective in reducing BHR in children with asthma. In addition, the level of asthma control and quality of life specific to AR were better in the irrigation group than those in the control group. Our results correspond with those of earlier studies in which symptom scores and need for medicines such as intranasal corticosteroids and antihistamines decreased after NSI in children with $\mathrm{AR}^{.22-26}$ In a prospective Chinese study, patients aged 2-15 years with AR who received combination treatment of NSI and intranasal corticosteroids for 12 weeks showed significant improvement of AR symptoms and reduced intranasal corticosteroid dose compared to those who used intranasal corticosteroids alone. ${ }^{23} \mathrm{~A}$ randomized double-blind study in Thailand reported that nasal symptom scores and antihistamine consumption significantly decreased after 4 weeks of hypertonic nasal irrigation. ${ }^{22} \mathrm{~A}$ recent systematic review proposed that NSI could be a safe and acceptable alternative to intranasal steroids and antihistamines in children with $\mathrm{AR}^{25}$

There have been only two previous studies investigating the effects of NSI on BHR in children. ${ }^{27,28}$ Tsao et al. compared $\mathrm{PC}_{20}$ before and after 12 weeks of NSI in children with asthma and AR. However, they could not reveal significant improvement in BHR after NSI, although NSI improved postnasal drainage, nasal congestion, and nocturnal cough in children with CRS. ${ }^{27}$ Oliveira et al. analyzed changes in $\mathrm{PC}_{20}$ before and 30 days after treatment with NSI in 12 children with asthma and AR as a control group to evaluate the effect of sinusitis treatments on BHR in children with sinusitis as well as asthma and $\mathrm{AR}^{28}$ They also did not find an increase in $\mathrm{PC}_{20}$ after one month of NSI in children with asthma and AR. The discrepancy between results of those studies and the present study may be due to the frequency and duration of NSI as well as patient compliance to treatment. We applied NSI as an adjunct to conventional medicines for asthma and AR twice a day for a longer duration than previous studies. In the present study, a trained nurse educated all subjects on how to perform NSI at their first clinic visit, and a co-researcher called or met subjects every month to improve their compliance with NSI.

Although NSI may be an effective treatment option for respiratory diseases, it is difficult to maintain compliance with NSI in the pediatric setting because of patient fear and intolerance. ${ }^{29}$ In the present study, however, mean irrigation frequency per week was 6 days, and about $60 \%$ of patients performed NSI completely on a daily basis without missing a session during the entire study period. Similarly, in our previous study, 63.6\% of children aged 4-13 years carried out NSI more than 4 days a week for at least 4 consecutive weeks during a mean follow-up duration of 6.2 months. ${ }^{14}$ Moreover, the highest rate of compliance was achieved in lower grade elementary school children, which comprises the majority of our study subjects. In that study, the need for surgical treatment of CRS was lower in the good compliance group than in the poor compliance group. ${ }^{14}$ However, $15 \%$ of patients in the irrigation group reported minor adverse events such as otalgia, ear fullness, or epistaxis in the present study, although no patients dropped out due to serious problems.
These results correspond to those of previous studies in which $8-23 \%$ of patients reported minor adverse events such as irritation or a burning sensation, indicating good safety and tolerability of NSI. ${ }^{8,10}$ Proper education is necessary in all children requiring NSI to reduce adverse events and improve compliance.

In previous studies, clinical improvement in AR is correlated with changes in various inflammatory mediators and cytokines involved in diverse Th2-mediated diseases. For example, soluble intercellular adhesion molecule-1 significantly decreased after NSI treatment in children with AR. ${ }^{30}$ Mechanical flushing of the nasal cavity with solution removes thick mucus, crusts, debris, allergens, histamines, and prostaglandins from the nasal cavity and paranasal sinuses. ${ }^{1{ }^{1,12}}$ It may also promote mucociliary functions by moisturizing the nasal mucosa and improving the ciliary environment. ${ }^{31}$ Although the exact mechanism for the effect of NSI on asthma and BHR remains unclear, it is plausible that reduced inflammation of the upper airways leads to decreased sensitivity of the lower airways to various stimulants. Epidemiologic, pathophysiologic, and clinical evidence supports that AR treatment decreases asthma symptoms. ${ }^{5,32}$ The proposed mechanisms improving asthma or BHR after treatment of AR include altered nasal-bronchial reflex, improved mouth breathing, and reduced aspiration of inflammatory products from the upper airway into the lower airway. ${ }^{33}$

Our study has several limitations. First, we did not fully consider the effect of seasonal changes on symptoms of AR and asthma, although we tried to avoid seasons with high counts of sensitized pollen in each patient. Fortunately, no differences were found in aeroallergen sensitization rates between the irrigation and control groups in the present study. However, the results are likely to be influenced by meteorological factors or ambient air pollutants. Second, the subjective symptom scores of the irrigation group may be biased because this study was not performed in a blinded manner. However, a double-blind, placebo-controlled clinical trial is impossible, as subjects will feel mechanical cleansing occurring. To overcome this bias, we chose the objective measurement of $\mathrm{PC}_{20}$ as a primary outcome. Additionally, the standard deviation of $\mathrm{PC}_{20}$ in the treatment group was higher than that in the control group, although there were no significant differences in the median values of $\mathrm{PC}_{20}$ between irrigation and control groups. It could affect responses to the conventional asthma management in the present study. Therefore, there is a possibility of statistically significant changes in clinical indices before and after treatment in the control group, if sample size is higher than in the present study. However, the strengths of our study rely on its prospective design, highly selected patients based on the strict criteria, and no loss to follow-up during the study.

In conclusion, treatment with NSI for 12 weeks improved BHR, asthma control status, and quality of life in children with asthma and AR. These results provide evidence of the clinical values of NSI in asthma and AR. NSI is a potential adjunctive treatment option as it is a simple, inexpensive, safe, and effective procedure. 


\section{Acknowledgment}

We thank Seonwoo Kim and Hyeoun Seon Ahn for statistical analyses.

\section{Conflict of interest}

The authors declare that there are no potential conflicts of interests with respect to authorship and/or publication of this article.

\section{Funding support}

This study was supported by the SMC Research and Development Grant \#SMO1161591.

\section{References}

1. Global Initiative for Asthma. 2016 GINA report, global strategy for asthma management and prevention [Internet].[place unknown]: Global Initiative for Asthma; c2016 [cited 2018 May 3]. Available from: https:// ginasthma.org/wp-content/uploads/2016/04/wms-GINA-2016-main -report-final

2. Yoo KH, Ahn HR, Park JK, Kim JW, Nam GH, Hong SK, et al. Burden of respiratory disease in Korea: an observational study on allergic rhinitis, asthma, COPD, and rhinosinusitis. Allergy Asthma Immunol Res. 2016; 8:527-34.

3. Brozek JL, Bousquet J, Agache I, Agarwal A, Bachert C, Bosnic-Anticevich $\mathrm{S}$, et al. Allergic Rhinitis and its Impact on Asthma (ARIA) guidelines -2016 revision. J Allergy Clin Immunol. 2017;140:950-8.

4. Suh DI, Lee JK, Kim JT, Min YG, Koh YY. Bronchial hyperresponsiveness in preschool children with allergic rhinitis. Am J Rhinol Allergy. 2011; 25:e186-90.

5. Licari A, Castagnoli R, Denicolo CF, Rossini L, Marseglia A, Marseglia GL. The Nose and the Lung: United Airway Disease? Front Pediatr. 2017; $5: 44$.

6. Lohia S, Schlosser RJ, Soler ZM. Impact of intranasal corticosteroids on asthma outcomes in allergic rhinitis: a meta-analysis. Allergy. 2013; 68:569-79.

7. Corren J, Manning BE, Thompson SF, Hennessy S, Strom BL. Rhinitis therapy and the prevention of hospital care for asthma: a case-control study. J Allergy Clin Immunol. 2004;113:415-9.

8. Hermelingmeier KE, Weber RK, Hellmich M, Heubach CP, Mosges R. Nasal irrigation as an adjunctive treatment in allergic rhinitis: a systematic review and meta-analysis. Am J Rhinol Allergy. 2012;26:e119-25.

9. King D, Mitchell B, Williams CP, Spurling GK. Saline nasal irrigation for acute upper respiratory tract infections. Cochrane Database Syst Rev. 2015:CD006821.

10. Chong LY, Head K, Hopkins C, Philpott C, Glew S, Scadding G, et al. Saline irrigation for chronic rhinosinusitis. Cochrane Database Syst Rev. 2016;4:CD011995.

11. Georgitis JW. Nasal hyperthermia and simple irrigation for perennial rhinitis. Changes in inflammatory mediators. Chest. 1994;106:1487-92.

12. Marchisio P, Varricchio A, Baggi E, Bianchini S, Capasso ME, Torretta S, et al. Hypertonic saline is more effective than normal saline in seasonal allergic rhinitis in children. Int J Immunopathol Pharmacol. 2012;25: 721-30.

13. Garavello W, Romagnoli M, Sordo L, Gaini RM, Di Berardino C, Angrisano A. Hypersaline nasal irrigation in children with symptomatic seasonal allergic rhinitis: a randomized study. Pediatr Allergy Immunol. 2003;14:140-3.

14. Hong SD, Kim JH, Kim HY, Jang MS, Dhong HJ, Chung SK. Compliance and efficacy of saline irrigation in pediatric chronic rhinosinusitis. Auris Nasus Larynx. 2014;41:46-9.
15. Instruction of nasal saline irrigation [Internet]. Seoul, Korea: Department of Otorhinolaryngology-Head and Neck Surgery, Samsung Medical Center;c2011 [cited 2018 Jun 25]. Available from http://www.samsung hospital.com/popup/pop_movie.jsp?movieURL=rtmp://fms.samsunghos pital.com/movie/hospital/noes.flv

16. Chai H, Farr RS, Froehlich LA, Mathison DA, McLean JA, Rosenthal $\mathrm{RR}$, et al. Standardization of bronchial inhalation challenge procedures. J Allergy Clin Immunol. 1975;56:323-7.

17. Crapo RO, Casaburi R, Coates AL, Enright PL, Hankinson JL, Irvin CG, et al. Guidelines for methacholine and exercise challenge testing-1999. This official statement of the American Thoracic Society was adopted by the ATS Board of Directors, July 1999. Am J Respir Crit Care Med. 2000;161:309-29.

18. Ferreira-Magalhaes M, Pereira AM, Sa-Sousa A, Morais-Almeida M, Azevedo I, Azevedo LF, et al. Asthma control in children is associated with nasal symptoms, obesity, and health insurance: a nationwide survey. Pediatr Allergy Immunol. 2015;26:466-73.

19. Bousquet J, Schunemann HJ, Samolinski B, Demoly P, Baena-Cagnani $\mathrm{CE}$, Bachert C, et al. Allergic Rhinitis and its Impact on Asthma (ARIA): achievements in 10 years and future needs. J Allergy Clin Immunol. 2012; 130:1049-62.

20. Jin JY, Yang HJ, Jeon YH, Kim KW, Kim WK, Park YM, et al. Development and validation of the questionnaire for quality-of-life specific to allergic rhinitis in Korean children (QQOL-ARK): a multicenter study. Korean J Asthma Allergy Clin Immunol. 2009;29:242-8.

21. Dweik RA, Boggs PB, Erzurum SC, Irvin CG, Leigh MW, Lundberg JO, et al. An official ATS clinical practice guideline: interpretation of exhaled nitric oxide levels (FENO) for clinical applications. Am J Respir Crit Care Med. 2011;184:602-15.

22. Satdhabudha A, Poachanukoon O. Efficacy of buffered hypertonic saline nasal irrigation in children with symptomatic allergic rhinitis: a randomized double-blind study. Int J Pediatr Otorhinolaryngol. 2012;76: 583-8.

23. Chen JR, Jin L, Li XY. The effectiveness of nasal saline irrigation (seawater) in treatment of allergic rhinitis in children. Int J Pediatr Otorhinolaryngol. 2014;78:1115-8.

24. Chusakul S, Warathanasin S, Suksangpanya N, Phannaso C, Ruxrungtham $\mathrm{S}$, Snidvongs K, et al. Comparison of buffered and nonbuffered nasal saline irrigations in treating allergic rhinitis. Laryngoscope. 2013;123:53-6.

25. Head K, Snidvongs K, Glew S, Scadding G, Schilder AG, Philpott C, et al. Saline irrigation for allergic rhinitis. Cochrane Database Syst Rev. 2018;6:CD012597.

26. Gutierrez-Cardona N, Sands P, Roberts G, Lucas JS, Walker W, Salib R, et al. The acceptability and tolerability of nasal douching in children with allergic rhinitis: A systematic review. Int J Pediatr Otorhinolaryngol. 2017;98:126-35.

27. Tsao CH, Chen LC, Yeh KW, Huang JL. Concomitant chronic sinusitis treatment in children with mild asthma: the effect on bronchial hyperresponsiveness. Chest. 2003;123:757-64.

28. Oliveira CA, Sole D, Naspitz CK, Rachelefsky GS. Improvement of bronchial hyperresponsiveness in asthmatic children treated for concomitant sinusitis. Ann Allergy Asthma Immunol. 1997;79:70-4.

29. Marchisio P, Picca M, Torretta S, Baggi E, Pasinato A, Bianchini S, et al. Nasal saline irrigation in preschool children: a survey of attitudes and prescribing habits of primary care pediatricians working in northern Italy. Ital J Pediatr. 2014;40:47.

30. Li H, Sha Q, Zuo K, Jiang H, Cheng L, Shi J, et al. Nasal saline irrigation facilitates control of allergic rhinitis by topical steroid in children. ORL J Otorhinolaryngol Relat Spec. 2009;71:50-5.

31. Campos J, Heppt W, Weber R. Nasal douches for diseases of the nose and the paranasal sinuses--a comparative in vitro investigation. Eur Arch Otorhinolaryngol. 2013;270:2891-9.

32. Wert AF, Posa D, Tsilochristou O, Schwerk N. Treatment of allergic children - Where is the progress (for the practicing allergist)? Pediatr Allergy Immunol. 2016;27:671-81.

33. Feng $\mathrm{CH}$, Miller MD, Simon RA. The united allergic airway: connections between allergic rhinitis, asthma, and chronic sinusitis. Am J Rhinol Allergy. 2012;26:187-90. 